\title{
HASIL BELAJAR KOGNITIF SISWA SD DALAM PEMBELAJARAN KONTEKSTUAL MEDIA MAZI (STUDI PADA SISWA SD KELAS TINGGI)
}

\author{
Wilfridus Muga \\ STKIP Citra Bakti, NTT \\ faneza_n@citrabakti.ac.id
}

\author{
Maria Susanti Oje \\ STKIP Citra Bakti, NTT \\ susanti.oje@gmail.com
}

\author{
Dek Ngurah Laba Laksana \\ STKIP Citra Bakti, NTT \\ laba.laksana@citrabakti.ac.id
}

\begin{abstract}
Abstrak
Penelitian ini bertujuan untuk mengetahui bagaimanakah hasil belajar kognitif yang diperoleh siswa SD kelas tinggi dengan menggunakan pembelajaran kontekstual meda mazi pada K-13 (tematik). Pengumpulan data dengan melakukan wawancara, observasi dan tes hasil untuk memperoleh nilai akhir pada siswa dengan menerapakan Meda Mazi. Tes tersebut disusun sesuai dengan Kurikulum 2013 yaitu pembelajaran Tematik, yang telah disesuaikan dengan silabus, Buku Guru dan Buku Siswa serta karakteristik kontekstual siswa yang telah dipadukan dengan Meda Mazi. Pembelajaran kontekstual merupakan pembelajaran yang dilakukan oleh guru dengan mengaitkan keadaan nyata yang dialami siswa secara alamiah. Untuk lebih mendalami keadaan kontekstual siswa Sekolah Dasar di kecamatan Golewa dan Golewa selatan Kabupaten Ngada, menerapkan Pembelajaran Kontekstual Meda Mazi, salah satu Sekolah Dasar yang sedang menerapkan Meda Mazi adalah SDI Malanuza yang sekaligus menjadi sekolah sasaran peneliti. Meda Mazi itu sendiri berarti duduk sambil berbicara untuk bermusyawarah atau bedsiskusi. Sehingga guru dan siswa bersama-sama menyelesaikan permasalahan yang dihadapi dalam proses pembelajaran. Berdasarkan penelitian penulis memperoleh hasil dengan nilai minimal rata-rata 81 , peresentase rata-rata $81 \%$, dengan jumlah siswa yang mencapai KKM sebanyak 25 orang/100\%. Berdasarkan hasil-hasil yang diperoleh peneliti menyimpulkan bahwa dengan menggunakan pembelajaran Kontekstual Meda Mazi akan memperoleh hasil kognitif nilai akhir dengan ketuntasan yang diharapkan.
\end{abstract}

Kata-kata kunci: hasil belajar, kontekstual, meda mazi

\begin{abstract}
This study aims to find out how the cognitive learning outcomes obtained by high level elementary school students using the contextual learning meda mazi on K-13 (curriculum 2013. Data collected by conducting interviews, observation and test results to obtain the final score on students by applying Meda Mazi. The tests were compiled in accordance with the Curriculum of 2013 lessons, which have been adapted to the syllabus, Master's Book and Student Books as well as the contextual characteristics of students that have been combined with Meda Mazi. Contextual learning is a learning done by the teacher by relating the real state experienced by students naturally. To deepen the contextual situation of elementary school students in Gole wa and Golewa subdistricts south of Ngada District, implement the Contextual Learning of Meda Mazi, one of the elementary schools that is implementing Meda Mazi is SDI Malanuza, which is also the target school of researchers. Meda Mazi itself means sitting while talking for a deliberation or discussion. So that teachers and students together solve the problems encountered in the learning process. Based on the research the authors obtained the results with an average minimum value of 81 , an average percentage of $81 \%$, with the number of students who reached minimum value as much as 25 people or $100 \%$. Based on the results obtained by the researchers concluded that by using contextual learning Meda Mazi will obtain the final cognitive value with the expected thoroughness.
\end{abstract}

Keywords: learning outcomes, contextual, mazi meda 


\section{Pendahuluan}

Dalam Undang-Undang No. 20 tahun 2003 tentang Sistem Pendidikan Nasional pasal (1) mendefenisikan pendidikan sebagai usaha sadar dan terencana untuk mewujudkan suasana belajar dan proses pembelajaran agar peserta didik secara aktif mengembangkan potensi dirinya untuk memiliki kekuatan spiritual keagamaan, pengendalian diri, kepribadian, kecerdasan, akhlak mulia serta keterampilan yang diperlukan dirinya, masyarakat, bangsa dan Negara.

Sedangkan menurut Mudyahardjo (Syaiful, 2012:3), Pendidikan merupakan suatu pengalaman belajar yang berlangsung dalam segala lingkungan dan sepanjang hidup. Ini berarti bahwa pendidikan dapat diperoleh atau dilakukan oleh siapa saja tanpa harus mengenal usia baik yang muda sampai yang tua karena pendidikan akan terus dijadikan sebagai pengalaman belajar di setiap tempat atau lingkungan manapun sepanjang hidup manusia itu sendiri.

Pendidikan di Indonesia saat ini, pada umunya sudah menggunakan Kurikulum 2013, baik mulai dari tingkat SD, SLTP atau sederajat sampai pada tingkat SLTA atau sederajat. Kurikulum 2013 pada dasarnya telah diimplementasikan mulai tahun 2013 yang dilaksanakan secara bertahap. Untuk mendukung keberhasilan pelaksanaan pembelajaran kontekstual berbasiskan kearifan lokal, Maka Wahana Visi Indonesia melaksanakan program pendampingan bagi guru di Sekolah Dasar agar memiliki pemahaman, sikap dan keterampilan yang sejalan dengan kurikulum 2013 namun yang berkarakter kontekstual. Dalam pelaksanaannya keberhasilan program pendampingan perlu didukung oleh ketersediaan panduan yang secara teknis mampu mimbimbing dan mengarahkan guru melaksanakan praktik pembelajaran kontekstual sesuai dengan kurikulum 2013 .

Tujuan pendidikan di Sekolah Dasar dewasa ini harus senantiasa dikaitkan dengan pendidikan dasar, karena Sekolah Dasar merupakan bagian dari sistem pendidikan dasar. Pendidikan dasar merupakan pendidikan yang lamanya 9 tahun yang diselengarakan selama 6 tahun di Sekolah Dasar (SD) dan 3 tahun di Sekolah Lanjutan Tingkat Pertama (SLTP) atau satuan pendidikan yang sederajat. Menurut Rasyidi (Taufiq, 2011), Sekolah Dasar (SD) pada hakekatnya merupakan satuan pendidikan atau unit lembaga sosial yang diberi amanah atau tugas khusus oleh masyarakat untuk menyelenggarakan penggalan pertama dari pendidikan dasar. Dengan demikian dapat diartikan bahwa pendidikan SD sebagai suatu proses yang tidak hanya sekedar memberikan bekal kemampuan intelektual dasar peserta didik dalam menulis, membaca dan berhitung, melainkan juga proses mengembangkan kemampuan dasar dalam aspek intelektual, sosial dan personal untuk dapat melanjutkan pendidikan ke jenjang berikutnya yaitu SLTP atau sederajat.

Dalam Kurikulum 2013 SD dilaksanakan pembelajaran tematik terpadu dan prosesnya dengan pendekatan saintifik. Penerapan pembelajaran tematik terpadu dengan pendekatan saintifik membawa implikasi perubahan dalam pembelajaran di SD. Perubahan itu mengakibatkan perubahan buku siswa, buku guru, sistem penilaian, pelaksanaan program remedial dan pengayaan, dan sebagainya. Oleh sebab itu harus dibutuhkan pedoman atau panduan yang sama dalam menyusun RPP bagi setiap kabupaten/kota seluruh Indonesia di masing-masing wilayah atau daerahnya.

Panduan Teknis Penyusunan Rencana Pelaksanaan Pembelajaran berbasis kontekstual (RPPK) adalah panduan operasional dari Pedoman Umum Pembelajaran yang diatur dalam Permendikbud Nomor 103 Tahun 2014 tentang Pembelajaran Kurikulum 2013 yang dikolaborasi dengan pembelajaran kontekstual hasil kerjasama dengan wahana visi Indonesia. Proses pembelajaran dirancang agar peserta didik secara aktif dan kreatif mengembangkan potensi dirinya dan potensi lingkungan untuk memiliki kekuatan spiritual keagamaan, pengendalian diri, kepribadian, kecerdasan, akhlak mulia, serta keterampilan yang diperlukan dirinya, masyarakat, bangsa, dan negara.

Kurikulum berakar pada budaya lokal dan bangsa memiliki arti bahwa kurikulum harus memberikan kesempatan kepada peserta didik untuk belajar dari budaya setempat dan nasional tentang berbagai nilai yang penting. Kurikulum juga harus memberikan kesempatan kepada peserta didik untuk berpartisipasi dalam mengembangkan nilai-nilai budaya setempat dan nasional menjadi nilai budaya yang digunakan dalam kehidupan sehari-hari dan menjadi nilai yang dikembangkan lebih lanjut untuk kehidupan di masa depan.

Selain itu, mutu pendidikan tidak selamanya bergantung pada faktor pendidik saja, peserta didik, penggunaan model, metode, media, bahan ajar dan sebagainya yang tentunya sangat berpengaruh untuk menghasilkan proses pengajaran yang lebih baik akan dapat meningkatkan mutu pendidikan yang akan dicapai. Namun, pendidik tetaplah akan menjadi unsur utama yang sangat penting dalam dunia pendidikan. Oleh karena itu, pendidikan hendakanya dirancang secara baik untuk menghasilkan mutu pendidikan yang berkualitas.

Hasil belajar dapat dilihat setelah seseorang melakukan aktifitas belajar sesuatu yang baru atau penyempurnaan dari sesuatu yang pernah dipelajari sebelumnya yang akhirnya akan membentuk suatu kepribadian dan dapat digambarkan dengan potensi yang berkaitan dengan tujuan pembelajaran. Untuk mendapatkan hasil 
pembelajaran yang baik, guru harus pandai memilih sekaligus merancang model pembelajaran yang harus disesuaikan dengan keadaan nyata siswa tersebut yaitu secara kontekstual. Sehingga siswa tidak menjadi pendengar pasif, namun siswa juga harus bisa berpendapat dan aktif dalam proses pembelajaran sehingga guru hanya sebagai fasilitator dan pemberi arahan bagi siswa, sedangkan untuk proses pembelajaran biarkan siswa yang lebih berperan namun harus berdasarkan bimbingan guru.

Berdasarkan hasil wawancara beberapa guru di SDI Malanuza mengatakan bahwa, Meda Mazi merupakan suatu strategi yang digunakan di SDI Malanuza dalam rangka meningkatakan keaktifan peserta didik saat berada di dalam kelas. Dimana tidak hanya guru saja yang dapat memecahkan suatu permasalahan dan mengambil suatu keputusan sendiri saja, namun siswa juga harus bersama-sama memutuskan suatu permasalan tersebut. Sebenarnya Meda Mazi itu sendiri berasal dari bahasa daerah setempat (Bajawa) yang dimana "Meda" berarti duduk dan "Mazi" berarti berbicara. Berdasarkan pengertian tersebut diambil kesimpulan bahwa Meda Mazi merupakan kegiatan yang dilakukan guru dan siswa untuk duduk bersama-sama dan berbicara bersama-sama pula pada saat proses pembelajaran berlangsung, atau dengan kata lainnya Meda mazi berarti belajar sambil duduk untuk bermusyawarah atau berdiskusi.

Untuk itu di SDI Malanuza, telah melakukan sebuah upaya dalam rangka meningkatkan mutu pendidikan dan pengajaran dengan mengaitkan pembelajaran di Sekolah dengan keadaan Kontekstual siswa dan cara menyampaikan materi pelajaran selalu berbasis lokal sehingga dapat meningkatan hasil belajar pada siswa kelas tinggi SDI Malanuza Kecamatan Golewa, dengan menggunakan RPP berbasis Kontekstual "Spirit Meda Mazi" dan menerapkan dalam proses pembelajaran di Kelas. Melalui model pembelajaran berbasis karakter Kontekstual dengan Spirit Meda Mazi peserta didik akan lebih aktif dan setiap proses pembelajaran berlangsung, baik guru maupun siswa sama-sama bermusyawarah untuk menyelesaiakan suatu permasalahan yang dihadapi dalam pembelajaran.

\section{Metode}

Penelitian ini dilaksanakan selama beberapa hari yang dilakukan di SDI Malanuza Kecamatan Golewa, Kabupaten Ngada. Subyek penelitian ini adalah siswa kelas IV SDI Malanuza dengan jumlah siswanya 25 orang. Sedangkan obyek yang diteliti pada penelitian ini adalah hasil belajar siswa dengan menerapkan Pembelajaran kontekstual Berbasis Spirit Meda Mazi. Metode pengumpulan data adalah dengan melakukan wawancara, observasi dan tes hasil belajar itu sendiri. Tes tersebut disusun sesuai dengan Kurikulum 2013 yaitu pembelajaran Tematik, yang telah disesuaikan dengan silabus, Buku Guru dan Buku Siswa. Instrument dalam penelitian ini adalah tes tertulis yaitu tes uraian sebanyak 15 soal setiap mata pelajaran dalam Tematik tema 2 sub tema 2. Metode analisis data menggunakan metode analisis statistik deskriptif kuantitatif.

\section{Hasil}

\section{Hasil dan Pembahasan}

Berdasarkan tes hasil belajar dengan menggunakan model yang biasa-biasa saja diperoleh hasil akhir dengan nilai yang belum optimal dan belum mencapai hasil yang diharapkan. Data hasil belajar siswa SDI Malanuza kelas IV Tematik Tema 2 Sub Tema 2 sebelum menggunakan Spirit Meda Mazi terdata sebagai berikut.

Tabel 1. Data Hasil nilai sebelum menggunakan Spirit Meda Mazi

\begin{tabular}{|l|c|c|c|c|}
\hline $\begin{array}{c}\text { Sebelum menggunakan } \\
\text { Meda Mazi }\end{array}$ & $\begin{array}{c}\text { Nilai rata-rata yang } \\
\text { diperoleh }\end{array}$ & $\begin{array}{c}\text { Hasil } \\
\text { presentasenya }\end{array}$ & $\begin{array}{c}\text { Jumlah siswa } \\
\text { yang mencapai } \\
\text { KKM }\end{array}$ & $\begin{array}{c}\text { Jumlah siswa yang } \\
\text { tidak mencapai } \\
\text { KKM }\end{array}$ \\
\hline $\begin{array}{l}\text { Siswa berjumlah: 25 } \\
\text { orang. }\end{array}$ & 62 & $62 \%$ & 7 orang (7\%) & 18 orang (93\%) \\
\hline
\end{tabular}

Berdasarkan tabel di atas dapat disimpulkan, sebelum menggunakan Meda Mazi dalam proses pembelajaran dengan jumlah siswa seluruhnya 25 orang, memperoleh nilai rata-ratanya 62 , dengan presentase $62 \%$, jumlah siswa yang mencapai KKM sebanyak 7 orang dan jumlah siswa yang tidak mencapai KKM sebanyak 18 orang. Hal ini berarti, lebih banyak siswa yang tidak mencapai KKM.

Dari hasil tes tersebut, peneliti melanjutkan dengan menggunakan pembelajaran kontekstual berbasis spirit meda mazi. Berikut data hasil akhir yang diperoleh dari siswa yang sama disajikan dalam Tabel 2. 
Tabel 2. Data Hasil nilai dengan menggunakan Spirit Meda Mazi

\begin{tabular}{|l|c|c|c|c|}
\hline $\begin{array}{c}\text { Menggunakan } \\
\text { Meda Mazi }\end{array}$ & $\begin{array}{c}\text { Nilai rata-rata yang } \\
\text { diperoleh }\end{array}$ & Hasil presentasenya & $\begin{array}{c}\text { Jumlah siswa yang } \\
\text { mencapai KKM }\end{array}$ & $\begin{array}{c}\text { Jumlah siswa yang } \\
\text { tidak mencapai } \\
\text { KKM }\end{array}$ \\
\hline $\begin{array}{l}\text { Siswa berjumlah: } \\
25 \text { orang }\end{array}$ & 81 & $81 \%$ & 25 orang $(100 \%)$ & 0 orang (0\%) \\
\hline
\end{tabular}

Setelah pelaksanaan perbaikan pembelajaran pertemuan pertama dan kedua, tidak menggunakan Meda Mazi dan dengan menggunakan Meda Mazi dalam proses pembelajaran hasil yang diperoleh siswa dinyatakan tuntas dengan nilai rata-rata sebesar 81 . Dengan nilai rata-rata 81 , presentase $81 \%$, dengan jumlah siswa yang mencapai KKM sebanyak 25 orang/100\% dan jumlah siswa yang tidak mencapai KKM 0\%. Berdasarkan hasil-hasil yang diperoleh peneliti menyimpulkan bahwa dengan menggunakan pembelajaran Kontekstual Meda Mazi akan memperoleh nilai akhir dengan ketuntasan yang diharapkan. Hal ini dikarenakan, pembelajaran Kontekstual Meda Mazi itu sendiri lebih menekankan pada pembelajaran yang benar-benar mengaitkan materi pembelajaran secara alamiah atau secara nyata sesuai dengan keadaan di sekitar siswa tersebut dan melalui Meda Mazi siswa akan begitu aktif dan lebih banyak mengeluarkan pendapat sesuai dengan apa yang mereka alami dalam kaitannya dengan materi pembelajaran.

\section{Pembahasan}

Pembelajaran kontekstual adalah suatu pembelajaran yang berupaya mengaitkan materi yang dipelajari dengan pengalaman siswa. Pembelajaran kontekstual tidak hanya mengharuskan siswa menghafal fakta-fakta, tetapi mendorong siswa mengkontruksi pengetahuan dibenak siswa itu sendiri (Depdiknas 2002). Dalam pembelajaran ini siswa didorong membuat hubungan antara pengetahuan yang dimilikinya dengan penerapannya dalam kehidupan mereka sebagai anggota keluarga dan masyarakat. Pembelajaran kontekstual berlangsung secara alamiahdalam bentuk kegiatan siswa bekerja dan mengalami, bukan sekedar mentransfer pengetahuan dari guru ke siswa saja. Pembelajaran kontekstual menekankan pada tingkat berpikir yang tinggi, yaitu berpikir divergen (kreatif).

Menurut Elaine B. Johnson (2007), kontekstual merupakan suatu pendekatan pendidikan yang berbeda, melakukan lebih dari pada menuntun para siswa dalam menggabungkan subjek-subjek akademik dengan konteks dalam keadaan mereka sendiri. Sedangkan menurut Komalasari (2010), pembelajaran kontekstual merupakan konsep belajar yang membantu guru untuk mengaitkan antara materi yang diajarkan dengan situasi dunia nyata dan mendorong pembelajar membuat hubungan antara materi yang diajarkan dengan penerapannya dalam kehidupan mereka sehari-hari.

Berdasarkan pendapat para ahli di atas, yang dimaksud dengan pembelajaran kontekstual dalam artikel ini adalah suatu konsep pembelajaran dimana dapat membantu guru mengaitkan materi yang diajarkannya dengan dunia nyata siswa tersebut sehingga dapat mendorong siswa untuk membuat hubungan antara pengetahuan yang dimiliki dengan penerapannya dalam keseharian mereka.

Untuk mendukung tercapainya pembelajaran kontekstual yang diharapkan agar dapat mencapai hasil pembelajaran yang memuaskan, pemerintah Kecamatan Golewa dan Golewa Selatan salah satunya di SDI Malanuza telah melakukan penerapan RPP berbasis Kontekstual Spirit Meda Mazi kearifan lokal berdasarkan Wahana Visi Indonesia, yang telah disesuaikan dengan karakter siswa serta keadaan lingkungan di sekitar siswa yaitu keadaan masyarakat setempat di Kab. Ngada. Pembelajaran berbasis Kontekstual "Spirit Meda Mazi", pada umumnya hanya digunakan oleh beberapa Sekolah Dasar yang ada di Kecamatan Golewa Kab. Ngada, sedangkan untuk seluruh Sekolah Dasar yang ada di Kab. Ngada lainnya belum menggunakan Spirit Meda Mazi. Namun, pemerintah khususnya Kependidikan, akan berusaha mengimplementasikan secara optimal kepada sekolah-sekolah sasaran pada Kabupaten Ngada di SD yang belum menerapkannya, Kabupaten Manggarai (Manggarai barat, Manggarai Timur) dan Kabupaten Nagekeo, yang nantinya akan disesuaikan dengan keadaan lokal daerah setempat. Sebenarnya pembelajaran meda mazi tidak jauh berbeda dengan model pembelajaran kooperatif dimana dalam model ini lebih menekankan pada kerja kelompok juga.

Meda Mazi itu sendiri memiliki makna, duduk untuk bermusyawarah bersama untuk memecahkan permasalahan (dalam hal ini materi pembelajaran) dan baik guru maupun siswa harus bersama-sama mencari solusi dari permasalahan tersebut. Di sini, tidak hanya guru saja yang terlihat aktif dan siswa hanya sebagai pendengar pasif, tetapi melalui pembelajaran kontekstual meda mazi diharuskan siswa untuk lebih aktif dan kreatif mengungkapkan apa yang dialaminya dan guru hanya sebagai fasilitator saja. 
Namun, guru tetaplah menjadi landasan yang paling utama, guru harus berkreatif untuk bisa memadukan secara jelih antara materi pembelajaran dengan keadaan sebenarnya siswa, agar siswa mampu berpikir secara mandiri dan sesuai dengan apa yang telah dialaminya. Guru juga harus pandai mengaitkan apa yang ingin diajarkan kepada siswa melalui penggunaan media atau alat peraga yang benar-benar ada dan dapat dijangkau oleh siswa di daerah tersebut. Oleh karena itu, tidak mudah untuk menerapkan Meda Mazi di SD, tetapi dibutuhkan guru yang berkreatifitas tinggi dan pandai mengatur materi dengan baik.

Dalam dunia pendidikan dan pengajaran, hasil belajar memegang peranan yang sangat penting. Dimana hasil belajar merupakan gambaran tingkat keberhasilan siswa dalam belajar. Menurut Hamalik (dalam Rusman, 2012:123), hasil belajar itu dapat terlihat dari terjadinya perubahan dan persepsi dan perilaku, termasuk juga perbaikan perilaku. Misalnya pemuasan kebutuhan masyarakat dan pribadi yang utuh. Hasil belajar merupakan proses yang kompleks dan terjadinya perubahan perilaku pada saat proses belajar diamati pada perubahan perilaku siswa setelah melakukan penilaian. Hasil belajar dapat dilihat setelah seseorang melakukan aktifitas belajar sesuatu yang baru atau penyempurnaan dari sesuatu yang pernah dipelajari sebelumnya yang akhirnya akan membentuk suatu kepribadian dan dapat digambarkan dengan potensi yang berkaitan dengan tujuan pembelajaran.

Hasil belajar adalah kemampuan yang dimiliki siswa setelah ia menerima pengalaman belajaranya (Rusman, 2012:123). Senada dengan pendapat tersebut Kingsley (dalam Kurniawan 2011:13) mengemukakan bahwa: “(1) Hasil belajar adalah keterampilan dan kebiasaan; (2) hasil belajar adalah pengetahuan dan pengertian; (3) hasil belajar adalah sikap dan cita-cita".

Menurut beberapa pendapat para ahli diatas, dapat disimpulkan bahwa hasil belajar merupakan setiap kemampuan akhir peserta didik yang sudah dimilki siswa setelah mendapatkan atau menerima pengalaman belajar dari pendidik. Hasil belajar ini yang akan sangat berguna bagi guru untuk mengetahui seberapa jauh tujuan pembelajaran telah dicapai dan seberapa jauh pula pembelajaran dimana peserta didik belum memahani apa yang telah diajarakan.

Berdasarkan wawancara dan hasil observasi di Kelas IV SDI Malanuza, guru kelas menyatakan dengan menerapkan pembelajaran kontekstual meda mazi agak begitu sulit namun kelihatan begitu mudah. Untuk mendesain sebuah RPP begitu mudah bagi guru untuk membuatnya, namun yang menjadi kesulitannya bagaimana guru tersebut harus bisa mengaitkan dunia sosial siswa dengan materi Tematik yang dimana tidak semua dalam pembelajaran Tematik materinya bisa diambil untuk dikaitkan dengan meda mazi itu sendiri. Namun, telah diakui guru kelas tersebut, bahwa hasil akhir yang diperoleh meningkat. Dan lebih banyak siswa yang tuntas dari pada siswa yang belum tuntas.

Dalam hal ini, penggunaan kontekstual meda mazi membawa perubahan hasil yang positif. Tidak hanya hasil kognitif yang memuaskan, hasil sikap dan keterampilan siswa juga meningkat. Hal ini dikarenakan, siswa diberi kesempatan seluas-luasnya untuk mengungkapkan dan mengembangkan bakat yang dimiliki dengan arahan dan bimbingan guru.

\section{Simpulan}

Berdasarkan hasil pembahasan di atas dapat disimpulkan bahwa dengan adanya Pembelajaran Kontekstual berbasis Spirit Meda Mazi dapat mencapai hasil belajar yang memuaskan bagi guru maupun siswa. Penerapan model kontekstual sebenarnya mampu menumbuhkan penguatan konsep pada siswa karena metode pembelajaran kontekstual menganut aliran kontruktivisme, dimana seorang siswa dituntut untuk menemukan pengetahuannya sendiri dan merupakan pembelajaran yang menekankan pada aktivitas siswa secara penuh baik fisik maupun mental. Sekolah Dasar Inpres Malanuza telah menerapkan model pembelajaran Kontekstual yang dipadukan dengan keadaan lokal yaitu Spirit Meda Mazi untuk lebih membentuk karakter siswa secara mendalam dan meningkatkan hasil belajar kognitif siswa. Walaupun menurut beberapa guru mengatakan cara menerapkannya agak sedikit sulit namun dengan Meda Mazi, tidak hanya guru saja yang terlihat aktif bahkan siswa akan terlihat sangat aktif dan bersemangat untuk mengikuti pembelajaran. Hal ini dikarenakan, proses pembelajaran yang terjadi telah disesuaikan dengan karakter dan keadaan nyata siswa di daerah tersebut. Melalui hasil yang telah diteliti, dengan Meda Mazi dapat meningkatkan hasil belajar siswa dengan perolehan nilai minimal rata-rata seluruh siswa SDI Malanuza Kelas IV sebesar 81, dengan presentase rata-rata 81\%, dengan jumlah siswa yang mencapai KKM sebanyak 25 orang/100\% dan jumlah siswa yang tidak mencapai KKM $0 \%$. 


\section{Daftar Pustaka}

Dasna, I W., Laksana, D.N.L., \& Sudhata, I G.W. (2015). Desain dan Model Pembelajaran Inovatif dan Interaktif. Jakarta: Universitas Terbuka Press.

Hamalik, O. (2011). Proses Belajar Menagajar. Jakarta: Bumi Aksara

Johnson, E.B. (2007). Contexstual Teaching and Learning. Bandung: Mizan

Lagong, A., Juita, E. \& Laksana, D.N.L. (2017). Desain Pembelajaran Kontekstual Spirit Kearifan Lokal Medamazi untuk Siswa Sekolah Dasar. Prosiding. $2^{\text {nd }}$ Annual Proceeding, November 2017 (ISSN: 2355-5106) STKIP Citra Bakti, Bajawa, NTT.

Laksana, D.N.L \& Rabu, K. (2016). Pembelajaran Kontekstual Berbantuan LKS Dalam Upaya Meningkatkan Pemahaman Konsep IPA dan Aktivitas Belajar Siswa SD. Jurnal Pendidikan Citra Bakti, 2(1), 79-89.

Laksana, D.N.L., Degeng, I N.S. \& Dasna, I W. (2017). Why Teachers Faces Misconception: A Study Toward Natural Science Teachers in Primary Schools. European Journal of Education Studies, 3(7), 667-679.

Rusman. (2012). Model-model Pembelajaran (Edisi Kedua). Jakarta: PT Raja Grafindo

Syaiful. (2012). Konsep dan Makna Pembelajaran untuk Membantu Memecahkan Problematika Belajar dan Mengajar. Bandung: PT Alfabeta

Taufiq, A. (2011). Pendidikan Anak di SD. Jakarta: Universitas Terbuka 